Article

\title{
Architecture and Steel. Reflection and Analysis on the Use of Steel Structures (in Sight) as a Concept in the History of Architecture
}

\author{
Inês D. D. Campos ${ }^{1,2, *(D)}$ and Luís F. A. Bernardo ${ }^{3}(\mathbb{D}$ \\ 1 Department of Civil Engineering and Architecture, University of Beira Interior, 6201-001 Covilhã, Portugal \\ 2 CIAUD, Research Center in Architecture, Urbanism and Design, Faculty of Architecture, \\ University of Lisbon, 1349-055 Lisbon, Portugal \\ 3 Centre of Materials and Building Technologies (C-MADE), Department of Civil Engineering and \\ Architecture, University of Beira Interior, 6201-001 Covilhã, Portugal; lfb@ubi.pt \\ * Correspondence: idc@ubi.pt
}

Received: 17 June 2020; Accepted: 29 July 2020; Published: 5 August 2020

\begin{abstract}
This is the first of two companion articles which aim to address the research on Architecture and Steel. In this article, some architectural projects are analyzed to show the potentiality to conjugate architectural conception and steel structures, as well as to show the contribution and influence from architectural history. This article also aims to contribute to the reflection of the knowledge and legacy left to us by several architects throughout the history of architecture in using aesthetic, visual and structurally safe profiled steel structures in architectural conception. The presented analysis and reflection are based on the characteristics and influences of the Industrial Revolution and, mainly, the Modern Movement, where the first housing projects came up with this constructive system, combined with the "simplistic" ways of living in architecture, highlighting the relationship with the place, cultural, spatial and typological references, the structural systems and associated materiality. In view of the diversity of alternatives allowed by the use of steel "Skeletons", modular and standardized, combined with a huge variety of existing materials and constructive complexity, well combined and interconnected, it is possible to obtain a final product whose characteristics seduce by their beauty and elegance. Moreover, the practical and functional comfort which allows the safeguarding of the architectural integration of such product, with the necessary serenity in space and nature, in full environmental integration, is also emphasized.
\end{abstract}

Keywords: steel architecture; modern architecture; industrial revolution

\section{Introduction}

With the Industrial Revolution, between the 18th and 19th century, "iron architecture" emerged from engineers who were in the art of building bridges, railway stations and pavilions for wide exhibitions, with magnificent drawings and economic solutions. In the 20th century, architects such as Mies van der Rohe, Philip Johnson, Richard Neutra and Rudolph Schindler marked the use of steel in architectural projects as a symbol of modernism. By assuming the steel structure in sight as an integral part of the architectural concept, this structural system allowed large glazed spans and open plans, with high freedom, functional and spatial flexibility, constituting the characteristics of a new architecture and a new way of living. Pierre Koenig was one of the architects who dedicated himself to develop projects with steel construction. He was known for participating in a program of innovative industrial houses, the Case Study Houses in Los Angeles. Together with Charles and Ray Eames, and Craig Ellwood, they defined such houses as poetic steel structures combining the strength and simplicity of this industrial system. They also proved that the mass production had the delicacy 
for use on a domestic scale, where the form and function were prominent, and its relations with the external nature were present, as an extension of the interior space.

Several examples built with this construction system exist. At the time, they were considered audacious and unlike everything that existed. The following and most emblematic works can be highlighted: the Crystal Palace in London, the Eiffel Tower in Paris, the Empire State Building and the Seagram Building both in New York, the buildings designated as 860-880 Lake Shore Drive Apartments in Chicago, the Golden Gate Bridge in San Francisco and the 25th Abril Bridge in Lisbon. Even with different architectural styles, these works remain timeless and with a delicate grandiosity which only steel can achieve.

The relationship between the "architectural design for housing" and the use of the "modular system in steel structures" in the technological/scientific field has been partially addressed in chapters from architectural and engineering monographs, where independent projects are described in engineering $\mathrm{Ph}$.D. theses, in articles published in periodic engineering journals on construction systems and, also, on projects developed by architects.

For architects, conceptual projects are part of the research, even when they are not built. The creative process is the way that architecture evolves, based on the influences that come from history, culture and the experiences from each architect. It includes experiences carried out with or without success, the application and combination of new techniques and technologies and the materiality combined with the form and place. The biggest challenge for architects is to be able to combine and interconnect the creative and individual system (concept) with the constructive precision, rigor and standardization of industrial processes. For the success of this interconnection, it is important that the architect masters the knowledge on the construction system with steel structures for the architectural conception [1].

To help architects in this goal, this article is the first of two companion articles related to the research on Architecture and Steel. In this article, some architectural projects are analyzed to demonstrate the potentialities to combine architectural conception with the use of steel structures, showing the contribution from the history of architecture and its influences. In each case study, how the structure influences and defines the living space and the relationship of the project with its surroundings is studied. The aim is to try to demystify the use of this constructive system today, highlighting its advantages and disadvantages.

\section{Contribution of History and Theory of Architecture}

In the early 20th century, mass production aimed to respond to the functional need to produce various components, to facilitate the daily lives of people and to increase the speed of construction of housing buildings. It is for this purpose that architects from the Modern Movement, such as Le Corbusier, associated the use of the "living machine" and mass production as a solution to solve the problem of the housing shortage at the time. They understood that objects produced in mass possess a geometric and ruled aesthetic which is pure, simple, organized and essential for modern individuals, who live in a new era, who are busier and with a fast pace and who appreciate and need order and simplicity [2].

For Le Corbusier, building houses in mass is related to inhabiting those houses, that is, building and living, as Heidegger thought. Thus, man inhabits the house which was built in mass. Here, Heidegger's thinking vanishes because in this process the houses are built by technicians. Because of this, the relationship of living space with the inhabitant during the construction process does not exist, while in the popular housings, the inhabitants are part of the construction and inhabiting process [3].

One of the last built works designed by Le Corbusier is the "The Heidi Weber Museum" or the "Le Corbusier Center" (1961-1967) in Zurich (Figure 1). This project was commissioned by a decorator, Heidi Weber, connected to the world of arts, and who wanted to honor the architect with a museum to publicize his work and thoughts. Le Corbusier chose a constructive system starting with the roof, made with a steel structure, which is disconnected from the building to constitute a shelter. The pavilion consists of prefabricated parts in steel, wood and colored enamel panels. This project 
marks a change in the type of material used by the architect, in which concrete and stone previously used in his architectural poetics are replaced with other materials such as steel and glass, leaving a mark for the future [2].

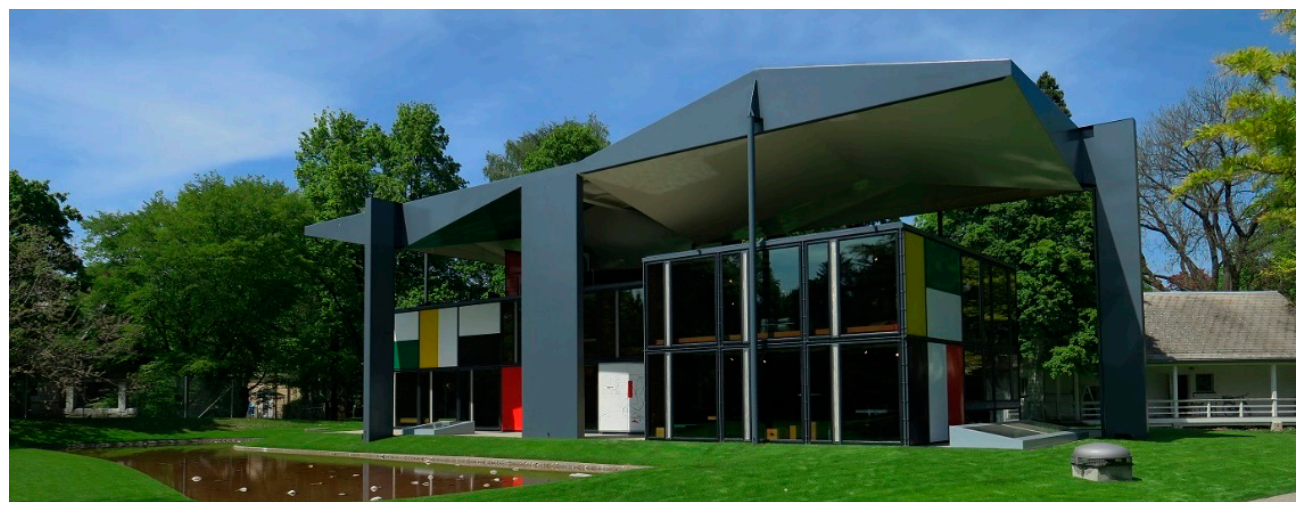

Figure 1. Le Corbusier Center, Zurich, 1961-1967 [4].

At that same time, when Le Corbusier studied this new housing, other architects like Walter Gropius began to explore constructive systems allowing, within uniformity, to achieve some differences in the final objects. During this new era of industrialization and, at the same time as Le Corbusier, Walter Gropius developed the idea of producing prefabricated elements for houses, which, when combined in different ways, gave architects several possibilities for results.

Gropius devoted himself to this topic because he believed that this type of housing freed people from most of the necessary work, providing more free time and a better quality of life. On the other hand, mass production allowed the product to be globalized more easily and would make it more economical. The themes studied and developed by Gropius were mobility, ease of transportation, adaptation to different cultures and climates, the possibility of creating several alternatives with the same building elements and their vertical or horizontal expansion.

In 1927, Walter Gropius designed two fully prefabricated houses (houses 16 and 17) for the Werkbund Exhibition in Stuttgart. House 17 (Figure 2) had a rectangular shape with a squared grid with $80 \mathrm{~cm}$ spacing which allowed a perfect modeling of the spaces and all the construction elements. The assembly system consisted of a steel frame system, composed with an auxiliary composite steel and wood structure, and, for insulation, cork panels were used. The exterior of the house was covered with steel sheet panels. The external plate finishing was combined with the windows, both with standard sizes as a function of the used plan grid. Gropius' investigations and experiments with such type of system allowed a breakthrough in innovative solutions and represented an important turning point at the time, which were important for future architects [4].

While Gropius developed his ideas, Buckminster Fuller created, as an inventor and designer, the book $4 D$ Timelock in 1928. This book intended to solve the problem of economic housing for everyone and was based on Henry Ford's mass production model. Fuller believed in the idea of producing economical houses like automobiles, with quality and modern materials to improve people's lifestyles. For his projects, he used lightweight materials and regular forms, such as circles and hexagons, to distribute the loads uniformly per the whole area, as well as to facilitate transportation by land or air. This type of module allowed him to place materials on top of each other, to create a vertical connection element for the circulations [2]. 

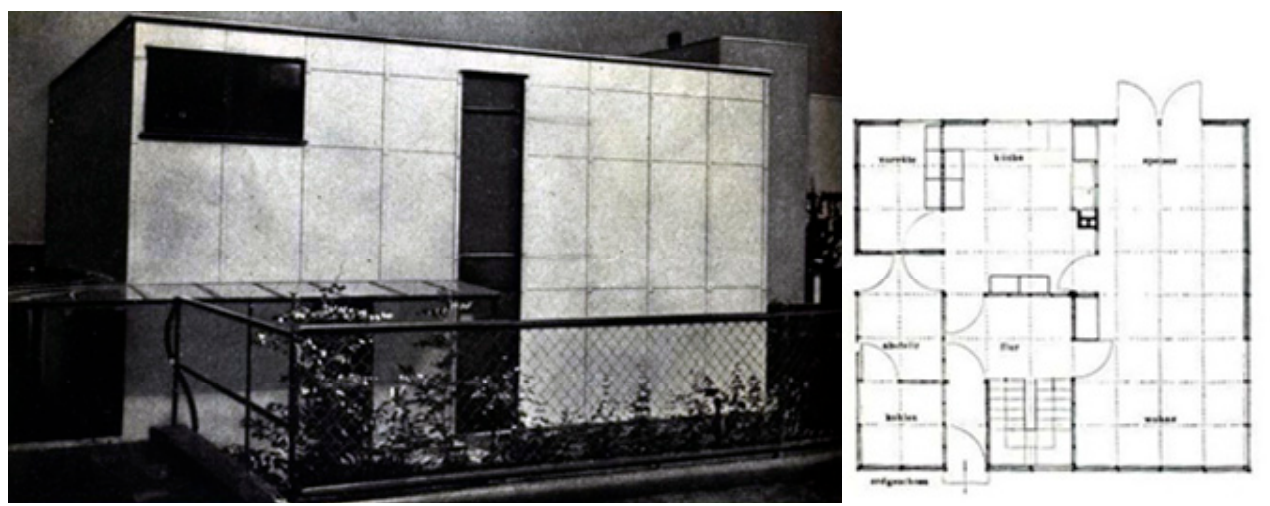

Figure 2. Experimental house by Walter Gropius for the Werkbund Exhibition in Stuttgart (house 17), 1927 [5].

In the transition from the 40s and 50s of last century, Jean Prouvé as a designer, builder and engineer, also developed prefabricated systems for houses. Prouvé did not understand why houses built with industrial materials continued to look traditional. It was essential for him that the projects translated new ways of living, to meet the new daily habits of each person at the time. In his opinion, the projects built with industrial materials could be aesthetically interesting with simple forms, although imposing, allowing the inhabitants to use spaces but to be harmonious and respond to day-to-day activities with which they could identify themselves.

The Meudon Houses in 1949 by Prouvé were quite economical (Figure 3). They were built with steel structures and the walls were prefabricated, allowing them to be placed inside the house according to the spatial needs of the inhabitant. People characterized these houses as being very modern, fragile and simple, as they were accustomated to traditional buildings, which are massive in character [6].

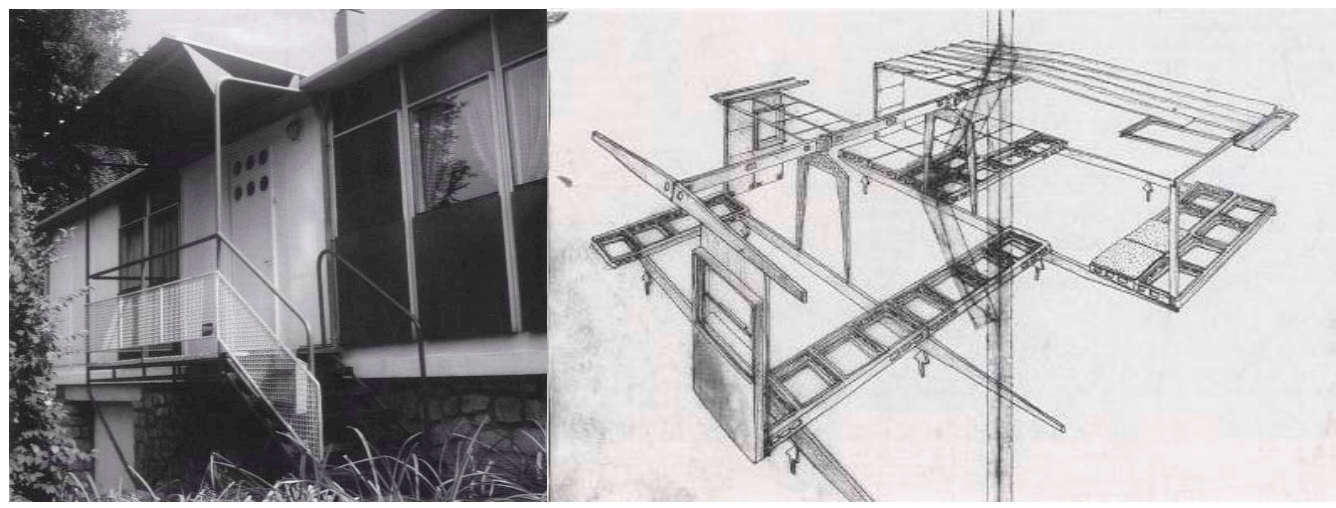

Figure 3. Meudon Houses by Jean Prouvé, Paris, 1949 [7].

Charles Eames also developed the taste for steel. He developed projects in steel structures and used industrial elements for mass construction. The Eames House in 1949, which belongs to the Case Study House Program in California, designed by Eames and Eero Saarinen, is composed with a modular steel structure, glass panels and composite asbestos and cement panels. This structure was thought to recreate furniture and symbolic spaces in the interior habitable.

\subsection{Potential Use of Steel in Architectural Design-Structural Steel System as a Concept}

Mies Van der Rohe repeated the following sentence several times, which, directed for teaching, represented the experience he lived: "Any education must start with the practical side of life, with the discipline path, going from the material, through the function, to the creative work." [8]. He interpreted architecture as the unique and simple combination of material, through technology and time, with form. 
This type of art, as a design concept, should be planned and built in detail and should be simple and pure. The synthesis of his works is the almost mystical stripping of forms and the nakedness of structures. His architectural ideas are based on the principle of construction which translates into absolute constructive clarity.

In the Viollet-le-Duc's architectural conceptions in the early 1860s, the aesthetic effect was not related to something fleeting, instead it was the result of a well-studied structure. For Mies Van der Rohe it was unthinkable to invent arbitrary forms, to copy historical motives and to create modern forms that were not motivated by the construction itself resulting from the structure. In his works, he clearly distinguished the structural elements from the closing elements (walls and openings) [4].

In the German Pavilion for the Barcelona International Exhibition in 1929 (Figure 4), with dividing panels freely arranged, Mies Van der Rohe combined the materials, the distribution and the space in a new concept, creating a spatial harmony of great attraction. This building is seen with great admiration and contemplation by people from all areas and knowledge backgrounds during their constant visits. The building shows the fluidity of its spaces due to the regular precision used by the architect. These qualities can be found in the teachings of the rigorous architecture from the past. This project uses a system of columns built with equal angle steel profiles to support a flat roof. It will be one of the starting points for the investigation of the applied modular system developed in the second companion article from the authors.
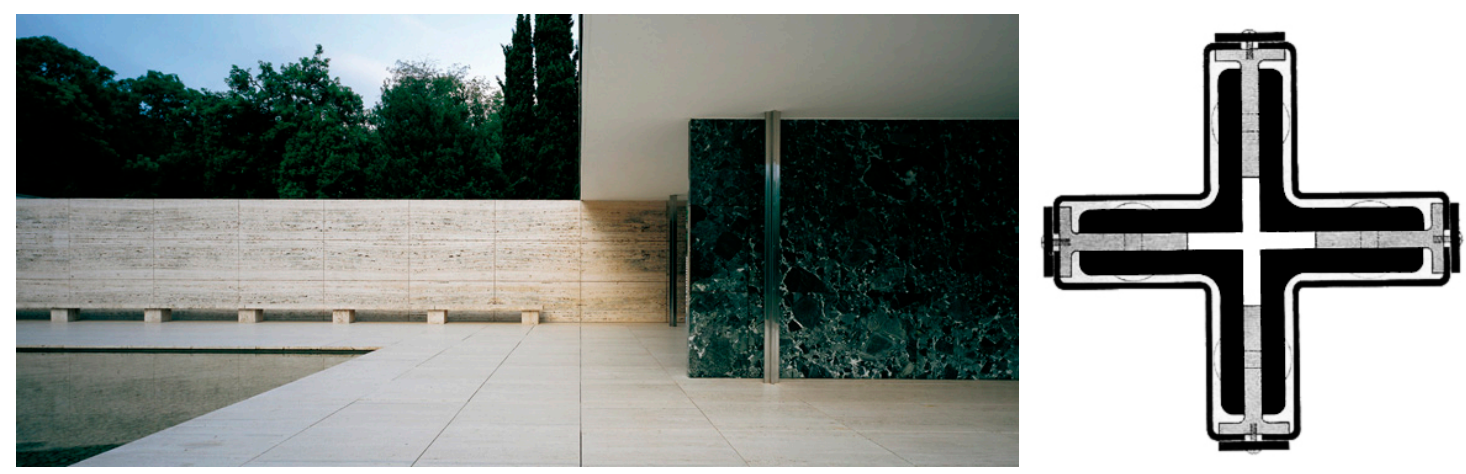

Figure 4. German Pavilion by Mies Van der Rohe, Barcelona International Exhibition, 1929 [9].

Mies Van der Rohe thought of architecture as something that is not tied to the current and actual moment, nor to eternity, but rather adapted to its time. For him, the work that expresses his time is the authentic one. The architectural vision of this architect is marked by order and sincerity, rigor and beauty, formalizing a spatial harmony. It is difficult to understand at first sight the whole process, effort and selflessness necessary for the result of his crystalline and exemplary works [8].

The structural steel system as an architectural concept implies being able to combine a set of factors, such as: interpretation of the place, program, conceptual idea and, at the same time, understanding the potentialities (positives and negatives) of this construction material, the advantages of rationalization, ability to plan and coordinate the construction phases from on-site production, allowing elements thought and designed in a project so that they can be produced and transported to the construction site for final assembly.

In the project coordination, the use of this steel construction system requires rigorous planning of the entire process, with a millimetric degree of detail of the structure to be built, so that the work assembly does not suffer unforeseen circumstances. The process begins with the "Previous Study" phase, presented in the form of sketches and diagrams, with the definition of the building typology and the construction system to be used, which result from a first approach with the client. This decision must be made at this stage, since the application of steel structures opens the range of the project development, because the structure made with industrial steel can be used in several ways. This system allows for modular coordination as a form of manufacturing planning, transportation and assembly, 
oriented for a better use of the materials, less waste of effort and a cost reduction at the construction site [1].

\subsection{Flexibility, Materiality and Context}

The flexibility of steel for housing construction allows for the easy mutation of spaces through mechanisms incorporated in the partition walls, so that their proportion and harmony do not change, but provide a differentiated experience of spaces according to the need at the time. In a modular system, this concept of flexibility allows the composition of differentiated spaces, depending on needs and functions.

In the housings, there are spaces that cannot be completely flexible, such as sanitary installations because there is a need for privacy, and the kitchens because of the need to avoid smells and steam throughout the house. For such spaces, there must exist the possibility to be hidden. The separation of these spaces can be made through fixed walls functioning as technical columns, where all necessary pipes for waters and sewers can be located, in addition to other technical equipment, such as electrical panels.

Cedric Price, as one of the most visionary architects of the 20th century, influenced architecture with his flexible housing systems. In spite of his little built legacy, his interventions were based at a time of the housing revolution that influenced some contemporary architects. He considered that housing should have a flexible structure: "The house is no longer acceptable as a pre-set ordering mechanism for family life" [10]. The architect's idea was to study people's way of life and to organize spaces accordingly.

The Steel Housing project in 1967 (Figure 5) is thought around the concept of flexibility of spaces, allowing them to be changed by moving the walls over time. This project can be characterized as the "living machine" where it is possible to control spaces as needed throughout the day. The structure is a modular system composed of frames with $2 \times 7 \mathrm{~m}$ in plan. It used a steel structure, composed of several frames, and organized as if it was a kit of pieces containing prefabricated walls, platforms, floors, stairs and ceilings, which could be assembled and disassembled as needed. This entire structure was versatile, allowing for a rapid and continuous change of spaces. The objective of each module was to respond to the coordination of the space of the house according to needs. In this sense, the space was designed to be flexible and to allow all possible changes. The modules were combined horizontally and vertically, with only two stories. This proposal was never built but became important in the field of research on changing people's habits during the $24 \mathrm{~h}$ cycle [10].
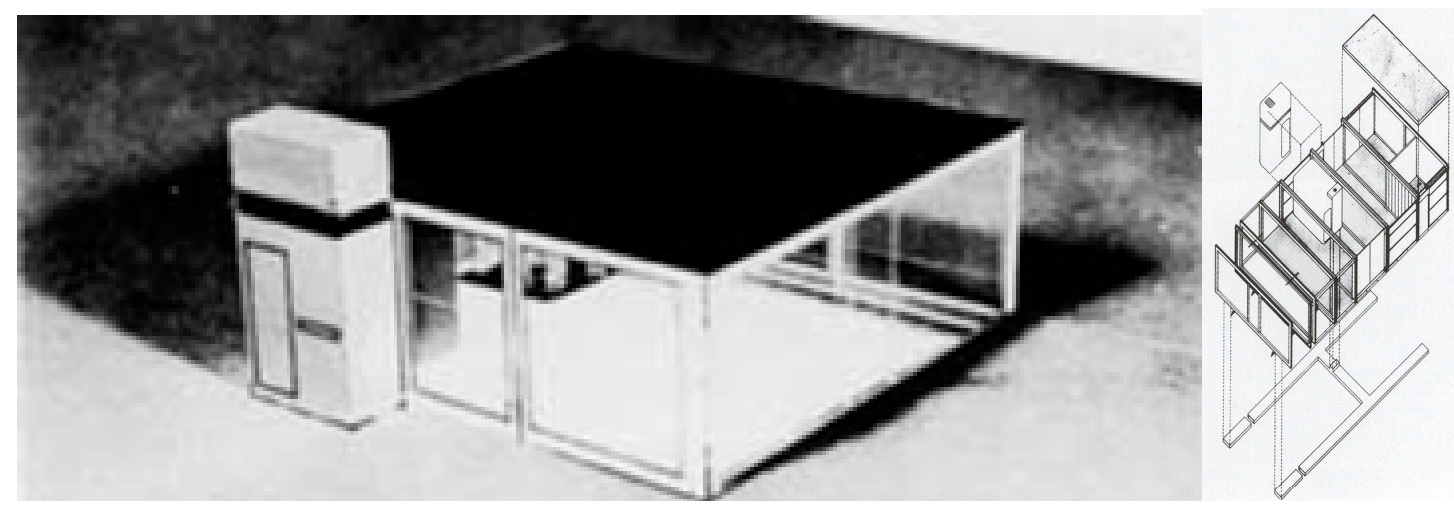

Figure 5. Steel Housing by Cedric Price, 1967: simple model, structure and connections [11].

Michael Hopkins built his own house in 1975 with two stories, using a structure with steel profiles to form cells, which were enclosed with steel panels or glass (Figure 6). The construction system was so simple that it could be assembled from elements of an industrial catalog, choosing piece by piece. This house started with a construction system through the connections of standard components, 
which was based on a structure of three-dimensional modules assembled from the addition of linear elements. The base of the geometric grid was square aluminum tubes and a connection point to connect them orthogonally. The whole house was organized according to these interconnected modules, allowing a diversity in the creation of interior spaces according to the needs of the inhabitant [12].

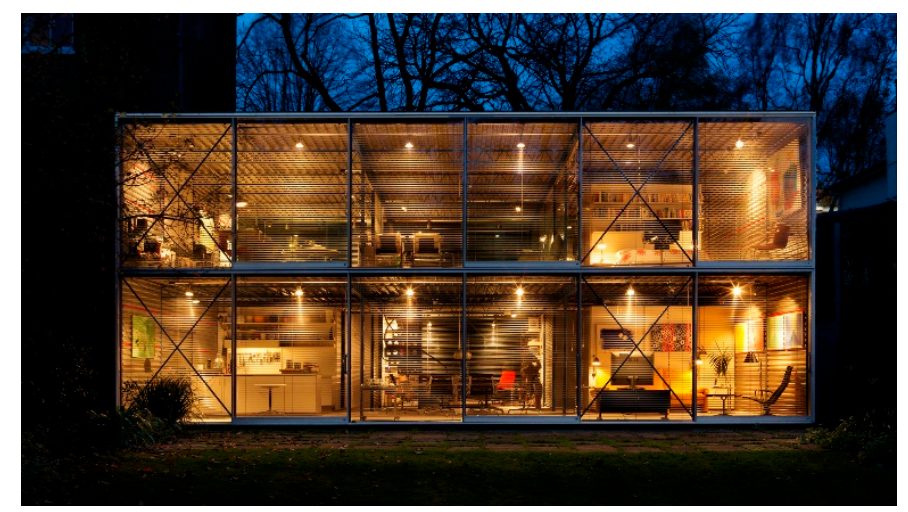

Figure 6. Michael and Patty Hopkins House, 1975-1976 [12].

Based on the same constructive conception, Richard Horden designed the Yacht house in 1984 (Figure 7). The house was developed on one single floor, starting from the squared tubular system, and composed of prefabricated floor panels, roof, facade and dividing walls. The courtyards of the house were empty modules, which connected the interior and exterior. The façade modules were composed of "semi-opaque" elements in slatted wood and glass panels. The main objective of this project was flexibility and the possibility to be adapted and increased over the years. The lightweight structure allowed it to be easily assembled in the construction site. The structure and the filling elements were built from standardized components and could be easily placed together in any module, forming a lightweight and weather resistant structure [13].
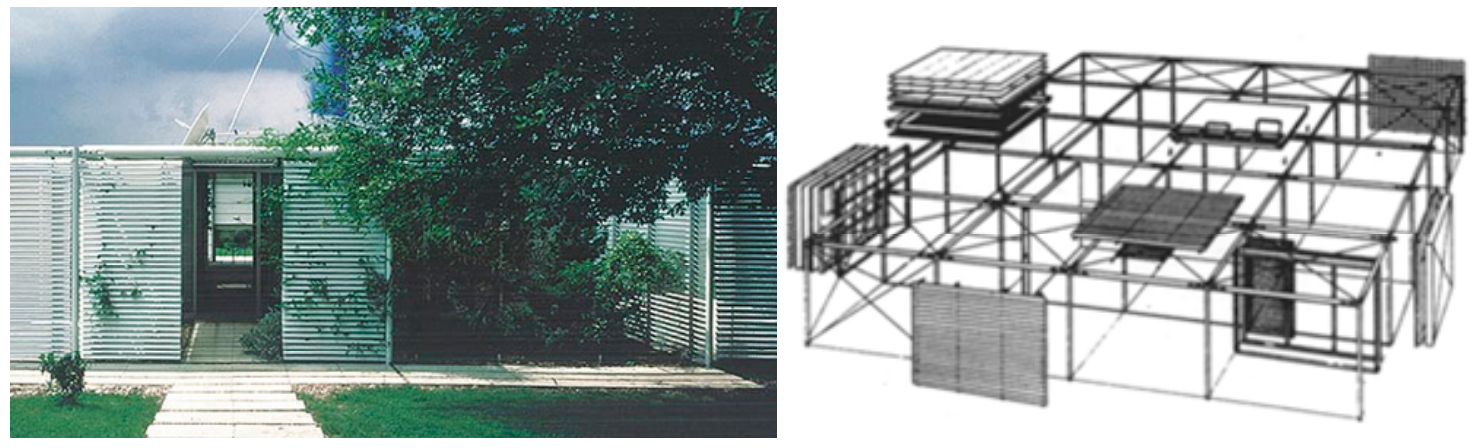

Figure 7. Yacht house by Richard Horden, New Forest, England, 1984 [13].

The previous two houses, although designed to be produced in mass, were used as models for other projects based on the modular system with steel structures, combined with the concept of simplicity, flexibility, lightness, speed and relationship with the place and integration.

\section{Architectural References-Modern and Contemporary Movement}

With the Modern Movement, the house became the most "desired" object to experience ideas and to affirm concepts, after a time of industrialization in which steel technology, in its pure form, was rarely used in housing projects. Some architects showed interest to design single-family and collective housings, in which the structure is part of the design concept. The steel structure became a new challenge for the project conception, becoming part of the architectural space, and evidenced by the transmitted lightness [6]. 
The functional characteristic of the modern space, according to Bruno Zevi in "Saber Ver a Arquitectura (Knowing See Architecture)", is based on the open plan, which should solve the problem of the house for the average family, with the new construction technique using steel and reinforced concrete, allowing light structures and open spaces. Bruno Zevi relates modern architecture to a Gothic dream in space, where new techniques allow audacity and the creation of spaces with large open spans, and the stained-glass windows become wide glass walls, allowing an absolute contact of interior/exterior. The internal partitions no longer respond to static functions, they are only thin separation elements, with the possibility of acquiring different shapes and moving freely, giving the possibility to combine different environments [14].

There are good examples in the history of architecture that show some of the advantages of using this construction system for housings. For example, in the 1950s, the "Case Study House" program, launched by Entenza in 1945, was aimed at promoting new housings where aesthetic, social, cultural and innovation ideals could be present. Nowadays, the competition "The Living Steel International Architecture" is another example, among other ones.

Such programs paved the way for a new perspective on the future of sustainability in housing architecture, new housing concepts, challenges and construction methods, leading to the fast development of urban areas.

Following this new ideology, and responding to the needs and difficulties architects faced by taking advantage of the industrial development, John Entenza decided to create the "Case Study House Program", where some architects at that time chose to design economical houses by applying concepts with prefabricated materials and profiled steel structures at low costs.

Having the option of using these new concepts, Pierre Koenig had to rectify his initial project for the House Koenig \#1 (Figure 8), as it was expensive. This made him realize the importance of modular planning and the use of standardized materials to make viable this type of construction for single-family housing. The chosen modular system was the $3 \mathrm{~m}$ squared, which, when put together, allowed him to organize the closed common spaces in a $12 \times 6 \mathrm{~m}$ structure and a $3 \times 6 \mathrm{~m}$ L-shaped garage.
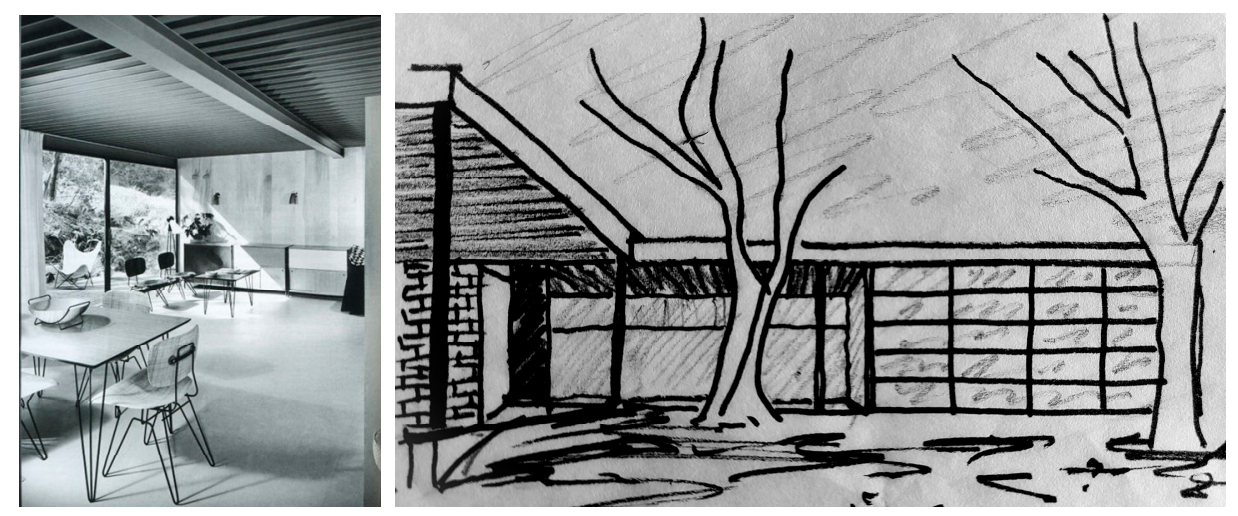

Figure 8. House Koenig \#1, Los Encinos Avenue, Glendale, Califórnia, 1950 [15].

The Case Study House \#8 (Figure 9), Eames House, by Charles and Ray Eames in California (1945-1949), is a project where the architect combined concepts such as industrialization, cinema and Japanese minimalism. In this project, the "new" technology and steel were applied in order to serve the society, creating personalized housings for each individual at a low cost, where the modular nature of the entire system allowed the management and coordination of the entire project, with the possibility to be expanded and reformulated, or to create other forms with the same components. It constitutes a good example of modular housing, with fast and easy production and assembly, that allows greater flexibility in changing spaces. The construction system demonstrated the possibilities that technology at that time provided, such as steel, glass, asbestos (recently removed from the market) and "cemesto" plates. Most of the exterior is glazed, transparent and translucent, although it is counteracted with 
areas covered with white painted coating panels and primary colors. The house consists of regular modules of $2.25 \mathrm{~m}$ in length and $6 \mathrm{~m}$ in depth, made of black steel industrial profiles, positioned horizontally like "Japanese shoji panels" [16].

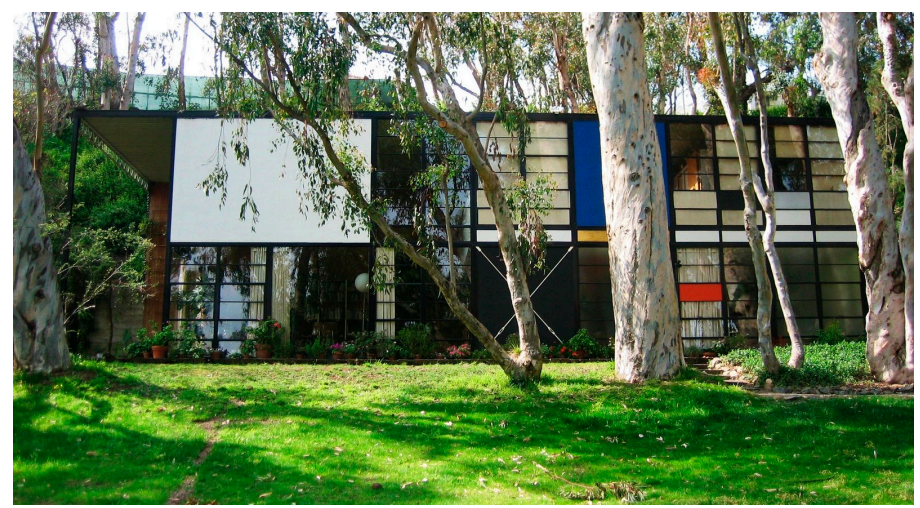

Figure 9. Case Study House \#8 by Charles and Ray Eames, Eames House, Santa Mónica, Califórnia, 1945-1949 [17].

At the same time as the "CSH program", in New York Philip Johnson designed the "Glass House" in New Canaan in 1949 (Figure 10). This project is considered one of the slenderest examples of American modernism, where the experience of space can be questioned because it is all in glass. The architect lived in it for 58 years. The architect himself refers to it as "the diary of an eccentric architect". In this project, Johnson had no concern with sustainability in architecture. The building consists of a "box" structured with black steel beams wrapped with glass from the floor to the ceiling. The interior space was divided by low walnut cabinets and a brick cylinder containing the toilet and in which the fireplace is embedded. The purpose of this house was to obtain a space to protect the inhabitant, but also continuing to allow for a relationship and a better use of the natural space [18].

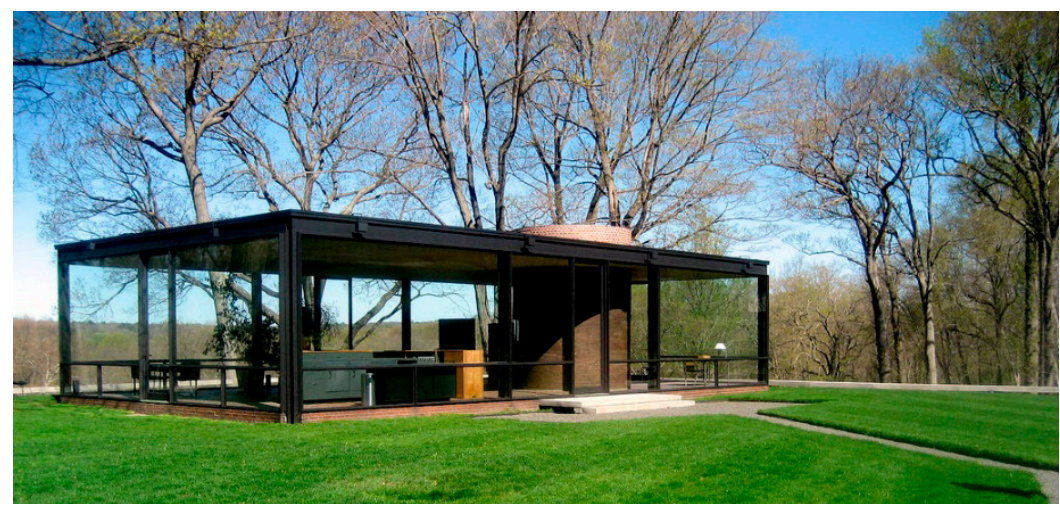

Figure 10. Glass House by Philip Johnson, New Canaan, 1949 [19].

With the same concept, the "Farnsworth House" by Mies Van der Rohe in Plano (Figure 11), Illinois, from 1950, is seen as an icon of modern architecture and one of the most recognized buildings in the definition of the architectural language of the 20th century. For Mies, error cannot exist in the search for perfection. In this sense, the choice of material (steel) and technologies for its application guarantee the rigor. As in the previous example, the main characteristics of this house are transparency, fluidity of spaces and the subtle differentiation that is almost nonexistent between public and private. The place of intervention for this project is in the middle of a forest with a lagoon and all the picturesque surroundings. The construction procedure has brought the latest ideas of "standardization" to the last consequences, strongly linking the interior with the exterior, providing a fluid, continuous and 
flexible space. The architect chose to lift the house from the ground with a stilt system to avoid flooding problems. The design is composed of a rigorous layout using minimal lines, promoting a language of illusion that it is "floating" on the ground, allowing it to be adapted to all seasons which are very strict in winter with floods and snow [20].

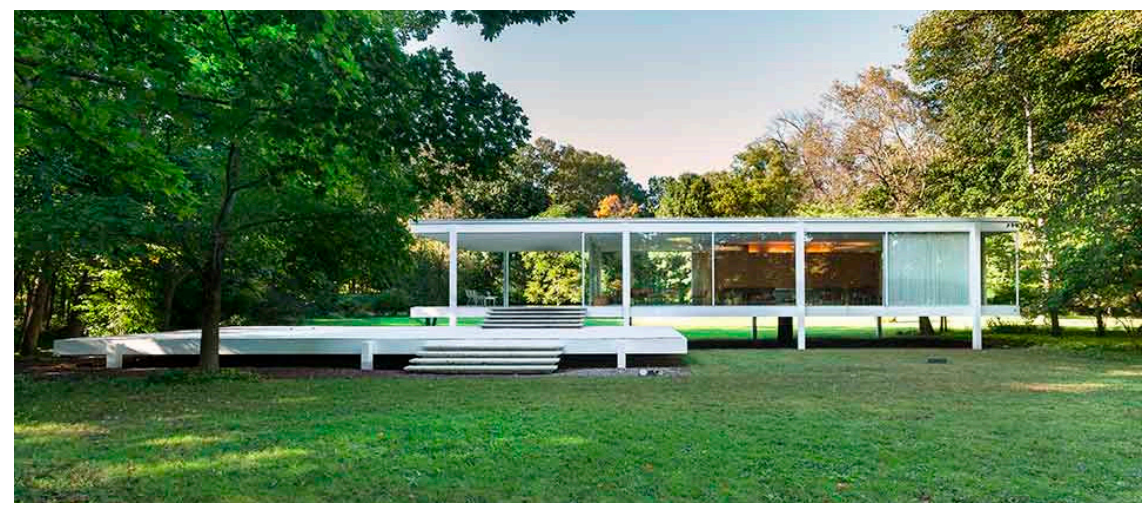

Figure 11. Farnsworth House by Mies Vand der Rohe, Illinois, 1950 [21].

The CHS\#21 (Figure 12) by Pierre Koenig's (1958-1960) represents the culmination of the architect's research in his interest in steel construction and the perfecting of constructive details. He designed an elegant and austere pavilion for a childless couple, located in an elevated place in Hollywood Hills. The concept of this project was that of the "universal house", which would be possible to be produced in mass. For this, the elements designed for its assembly incorporated only two types of details for the columns, allowing any element to be used for various solutions. It is a minimalist project, with contained spaces that open to exterior areas designed with water mirrors all around the house. The geometric shape of the house is even more evident with its flat roof, which is built with exposed ribbed steel sheets. The house was designed in a steel structure, consisting of columns and beams, in modules with 10 by 22 feet sections ( $1 \mathrm{foot}=30.48 \mathrm{~cm}$ ), under which glass walls were mounted with alternated cladding steel and plaster panels [22].
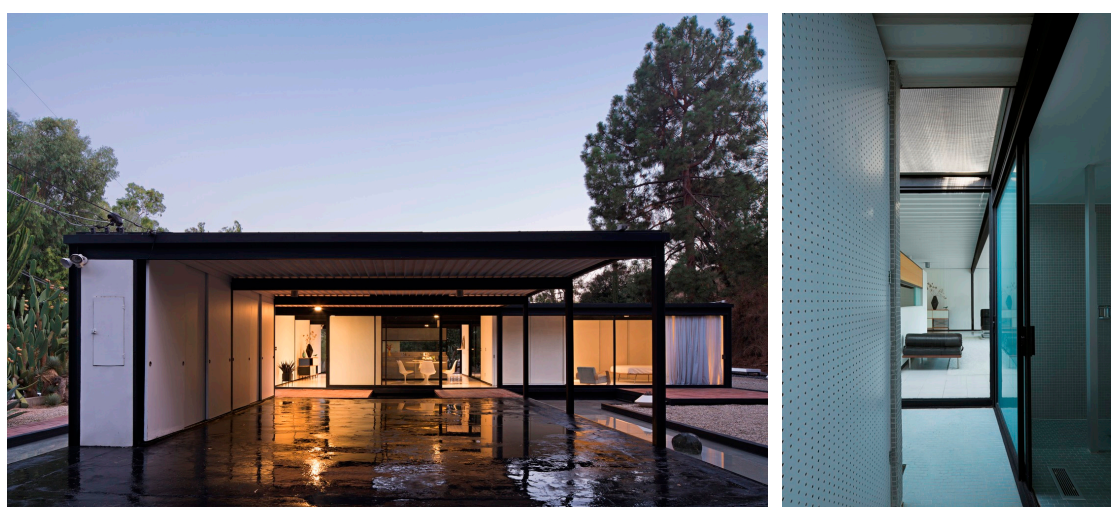

Figure 12. CSH\#21 by Pierre Koenig, West Hollywood, 1958-1960 [23].

The way of living is changing. The economy requires that homes are increasingly smaller and lack quality in spaces. Could this type of housing be able to respond to the functional and cultural needs of our current lifestyle? Could it be adapted to the different cultures in the world?

In 2005, the World Steel Association launched the "Living Steel" program to show why steel is a good bet for the construction of preeminent housing, especially at a low sustainable cost. This program was developed with the main objective of becoming a forum for submitting proposals in which the steel industry would be the protagonist of the project conception, from architects around the world, 
to respond to the needs of efficient and responsible housing. To make it work, all the teams had to demonstrate that steel was the distinctive building material for low-cost sustainable housing [24].

The concept of the SymHouse proposal (Figure 13) is the biological symbiosis of the interaction between two living organisms, man and the living (house), in which, in the flexible interior, it is the inhabitant who controls. Stuart Piercy said that "there is a contrast between western-style houses which are in general closed with the permeability of subtropical architecture." [22]. Here, the architects used several layers that allowed forward or backward movement, seeking the essence of Kolkata (Calcutta) in India. The steel doors were designed based on the Indo-Islamic culture, protecting from rain and sun, creating some privacy as the interior doors are made of glass for a greater amplitude to the outside.

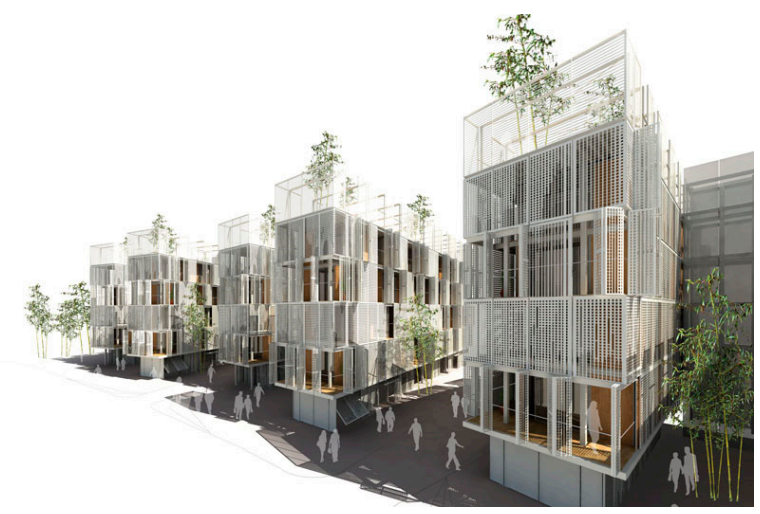

Figure 13. SymHouse by Piercy Conner, United Kingdom, Living Steel International Architecture, India, 2005 [24].

The construction techniques used in this project, based on the program for low-cost apartments, are the same as those used in the construction of offices, being quickly built in the factory, and assembled on the construction site. The structure is made of steel and the slabs are made of lightweight concrete, with ribbed metal sheets used as composite slabs. The exteriors are covered with perforated metal screens which, as the sun moves in the sky, create patterns inside, and, at night, provide light plays with the internal lights. The shape of the buildings maximizes natural light and ventilation. At the top of the buildings, there are terraces with gardens, and the bedrooms include "mezzanines" over patios at the level of the living rooms, allowing for a visual and real extension of the spaces.

With the use of steel in housing construction, it is possible to create lightweight, elegant and transparent structures, with the potential for large openings and spatial flexibility. This minimalist simplicity and structural slenderness allow for an interconnection between the interior and the exterior, making the houses perfectly integrated in the place.

\section{Conclusions}

With the industrialization, new materials produced in mass were used, allowing the study and development of new ways of living. One of the drivers of this change was Le Corbusier with his concept of "living machine". He redefined the existing values and introduced new concepts, with the aim of improving the quality of life of people in the private space. There was a group of architects who innovated and implemented the construction of single-family houses with steel structures. The structures were left in sight, taking advantage of this rising material, which is currently mostly used in large architectural and industrial works. The group that participated in the "Case Study House" program created by John Entenza, aimed to create economical and unpretentious houses that would respond to the needs of the inhabitants and that would be more functional and simple, with a better organization and flexibility of living spaces and with larger usable areas, using prefabricated materials. 
From that time, the concept of "living" has been thought and rethought by several architects, using industrialized processes, and giving a quick response to the lack of housing that existed at the time due to the rural exodus. Currently, it responds to the changes in ways of living influenced by globalization and the interchange of cultures, and the need for constant changes imposed by these intercultural and socioeconomic changes.

Many of the innovative solutions of modular systems, which were created throughout history, are interpreted as isolated objects that can be placed anywhere, but that do not belong anywhere; they are almost habitable sculptural works. In order to be characterized as architecture, it is important to combine concepts that must be part of the creative conception of the architectural project, namely: the study of the living space, the relationship of housing with the place (the identity of the place), the structural system as a concept, the modular system and the time and space factors, and the flexibility, materiality and context of the combination of architecture with the steel structure in sight.

The case studies analyzed in this article, being unique works and without repetition, allowed the understanding that it is fundamental to think about the project as a whole-structure and architecture. It is necessary to define the living spaces using the lines-the steel structure-as a network which in architectural design defines the spaces to inhabit.

After the study of this type of architecture, several constructive and historical contributions can be pointed out, namely: the speed of construction, a work always being clean and precise and with minimum errors which can be masked with covers, the lightness conveyed by their framing, the perfect relationship with the surroundings, the permeability and flexibility of spaces which easily allows changes. This type of architecture is very suitable to the pandemic situation that we have been experiencing, which has given people an understanding that houses were not built to remain.

After studying and analyzing this topic, the second companion article presents and discusses the development of an innovative prototype in a steel structure, where the acquired knowledge is applied. It consists of a modular system applied to single-family housing, in which steel remains part of the design concept, not only as a structural element, but also as an aesthetic element. The needs of contemporary "Living" are reinterpreted, with all the changes and cultural influences due to globalization, comparing it with the "Living" in Portuguese popular architecture, which has a simplistic character and minimal spaces, and referring it to a given place.

Author Contributions: I.D.D.C. investigated the topic and wrote the article. L.F.A.B. revised the article. All authors have read and agreed to the published version of the manuscript.

Funding: This research received no external funding.

Conflicts of Interest: The authors declare no conflict of interest.

\section{References}

1. de Campos, I.D. Concepção Arquitectónica e Estruturas Metálicas em Habitação, Sistema Modular Espacial Aplicado (Architectural Conception and Steel Structures for Housing. Applied Spatial Modular System). Ph.D. Thesis, University of Beira Interior, Covilhã, Portugal, 2015. (In Portuguese).

2. Gössel, P.; Leuthäuser, G. Arquitetura No Século XX (Architecture in the 20th Century); Taschen: Lisbon, Portugal, 2001. (In Portuguese)

3. Heidegger, M. Construir, Habitar, Pensar. [Bauen, Wohnen, Denken] (Building, Dwelling, Thinking). In Martin Heidegger, Vortrage Und Aufsatze; Pfullingen: Verlag Vittorio Klosterman, Germany, 1954. (In Portuguese)

4. Archdaily. Último Edifício Projetado Por Le Corbusier (Last Building Designed by Le Corbusier). 2020. Available online: https://www.archdaily.com.br/br/918082/ultimo-edificio-projetado-por-le-corbusier-ereaberto-em-zurique (accessed on 29 March 2020).

5. Proyectos 7/Proyectos 8. Vivienda Experimental (Experimental House), Walter Gropius. 2020. Available online: https://proyectos4etsa.wordpress.com/2012/05/08/vivienda-experimental-para-la-werkbund-exhibitionwalter-gropius-stuttgart-1927/ (accessed on 29 March 2020).

6. Curtis, W.J.R. Modern Architecture since 1900, 3rd ed.; Phaidon: London, UK, 1996. 
7. PROYECTOS 7/PROYECTOS 8. Casas De Meudon. 2020. Available online: https://proyectos4etsa.wordpress. com/2012/04/05/casas-de-meudon-jean-prouve-meudon-paris-1949/ (accessed on 29 March 2020).

8. AAVV. De aço e Vidro era o Mundo de Mies Van der Rohe (Steel and Glass was the World of Mies Van der Rohe). In Jornal do Brasil; Binário: Arquitectura, Construção e Equipamento: Lisboa, Portugal, 1969; pp. 222-224. (In Portuguese)

9. Fundació Mies Van Der Rohe Barcelona. 2020. Available online: https://miesbcn.com/the-pavilion/ (accessed on 29 March 2020).

10. Price, C. The Square book; Wiley Academy: London, UK, 2003.

11. Socks. 2020. Available online: http://socks-studio.com/2016/04/14/cedric-price-housing-research-1971-andthe-steel-house-1967/ (accessed on 29 March 2020).

12. Hopkins Architects 2020. Hopkins House. Available online: https://www.hopkins.co.uk/projects/7/85/ (accessed on 29 March 2020).

13. HCL Architects. The Yacht House-Hampshire, UK. 2020. Available online: http://www.hcla.co.uk/projects/ type/the-yacht-house (accessed on 30 March 2020).

14. Zevi, B. Saber Ver a Arquitectura (Knowing to See Architecture); Ed Martins Fontes: São Paulo, Brasil, 1996. (In Portuguese)

15. Usmodernist. Pierre Koenig. 2020. Available online: https://usmodernist.org/koenig.htm (accessed on 29 March 2020).

16. Koenig, G.; Eames, C.R. 1907-1978, 1912-1988, Pioneiros do Modernismo no Pós-Guerra (Postwar Modernism Pioneers); Koln: Taschen, Público, 2007. (In Portuguese)

17. Lateral Casa Eames. Available online: https://www.essenciamoveis.com.br/blog/simplesmente-a-casa-doseames/wwwcgarchitectcom-2/ (accessed on 29 July 2020).

18. Weston, R. A Casa No Século Vinte (The House of the Twentieth Century); Editorial Blau: Lisboa, Portugal, 2002. (In Portuguese)

19. Archdaily. The Glass House/Philip Johnson. 2020. Available online: https://www.archdaily.com/60259/adclassics-the-glass-house-philip-johnson (accessed on 29 March 2020).

20. Zimmerman, C. Mies Van Der Rohe: 1886-1969, a Estrutura Do Espaço; Ed Taschen GmbH: Hohenzollernring, Germany, 2010. (In Portuguese)

21. The National Trust for Historic Preservation. Available online: https://farnsworthhouse.org/ (accessed on 29 March 2020).

22. Jackson, N. Pierre Koenig, A View from the Archive; Getty Research Institute: Los Angeles, CA, USA, 2019.

23. Archdaily. Pierre Koenig's Famous Case Study House \# 21 Can Be Yours. 2020. Available online: https://www.archdaily.com.br/br/800434/a-famosa-case-study-house-number-21-de-pierre-koenigpode-ser-sua-pelo-preco-certo (accessed on 29 July 2020).

24. Foley, G. Houses of Steel, Living Steel's International Architecture Competitions; Crafti, S., Ed.; Images Publishing Dist Ac: Mulgrave, Australia, 2009; p. 24. Available online: https://www.mgsarchitecture.in/architecturedesign/projects/397-symhomes-mk-1-new-wave-of-architecture-in-india.html (accessed on 29 July 2020).

(C) 2020 by the authors. Licensee MDPI, Basel, Switzerland. This article is an open access article distributed under the terms and conditions of the Creative Commons Attribution (CC BY) license (http://creativecommons.org/licenses/by/4.0/). 